various ways until finally they achieved language, or if they were not wagging their tongues, how their quite other communication system turned into language. As linguist Pulleyblank said, Hockett's "brilliantly successful mutation" won't do. The absence of stepping stones from the nonlinguistic to the linguistic is precisely what makes the schema Athena-like.

5. Finally, the focus of my paper is on the possibility of an evolutionary semantics, specifically on what is in the way of forging such a semantics. It is this task in which I am interested. Clearing the path toward this task and the task itself I believe to be of momentous import to philosophy and to the values people hold in their everyday and professional lives. For these very reasons I do not believe an evolutionary semantics to be simply a matter of recording differences and similarities between us and them, and then admonishing ourselves to act in certain more putatively humane ways. An evolutionary semantics should itself carry us over into a morality-and this on the basis of the sensemaking it requires, a sense-making in which objects of study are recognized as subjects in their own right.

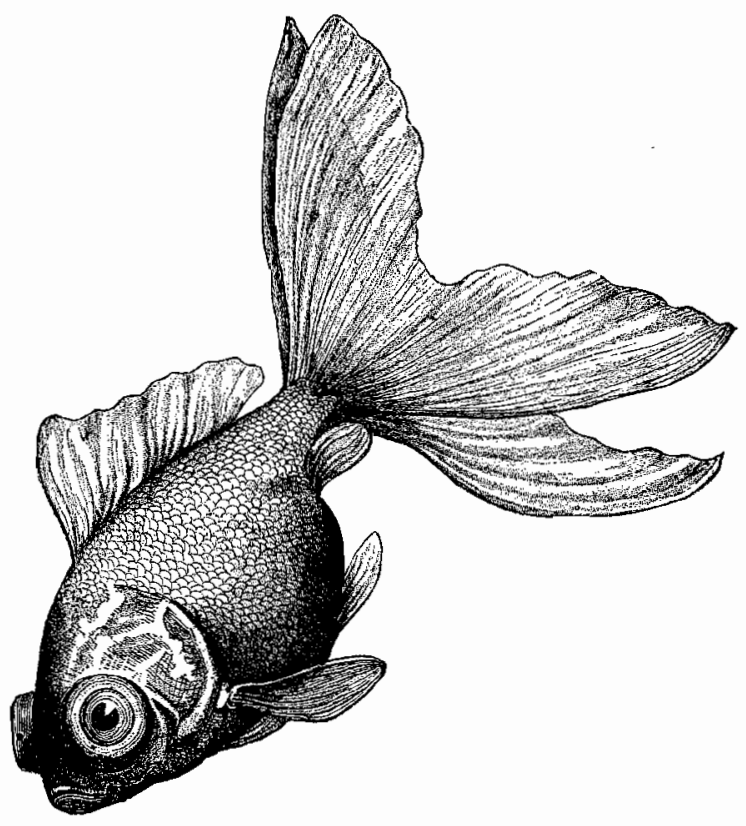

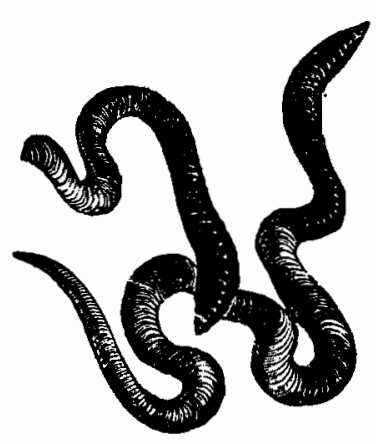

\section{BOOKS RECEロVED}

Eugene C. Hargrove (ed.)

THE ANIMAL RIGHTS / ENVIRONMENTAL ETHICS DEBATE

The Environmental Perspective

Albany: SUNY Press, 1992

preface, $261 \mathrm{p}$, index

$\$ 14.95$ paper

Brenda Peterson

NATURE AND OTHER MOTHERS

Reflections on the Feminine in Everyday Life

New York: Harper Collins, 1992

preface, $216 \mathrm{p}$

$\$ 22.00$ hardback

Angela Royston

DINOSAURS

New York: MacMillan, 1991

$21 \mathrm{p}$

$\$ 6.95$ hardback

Angela Royston

JUNGLE ANIMALS

New York: MacMillan, 1991

$21 \mathrm{p}$

$\$ 6.95$ hardback

C. C. W. Taylor (ed.)

ETHICS AND THE ENVIRONMENT

Proceedings of a Conference held at Corpus Christi

College, Oxford 20-21 September 1991

Oxford: Corpus Christi College, 1992

$97 \mathrm{p}$

f6 sterling, paper 